\title{
Effect of the use of silver nanocrystals and silver sulfadiazine in the management of soft tissue lesions
}

\author{
Cristian Tineo' \\ Cinthia M Nuñez ${ }^{2-4}$ \\ Ouel Sosa ${ }^{1,5}$ \\ Dahiana Pichardo' \\ Juan Luis Hernández' \\ Gustavo Collado 3 \\ 'Department of Surgery, José María \\ Cabral y Báez Regional and University \\ Hospital (HRUJMCB), ${ }^{2}$ Department of \\ Surgery, Dr. Arturo Grullòn University \\ and Childrens Hospital Burn Unit \\ (HIRUDAG), ${ }^{3}$ Department of Surgery, \\ Santiago Metropolitan Hospital \\ (HOMS), ${ }^{4}$ Department of Medicine, \\ Mother and Master Pontifical and \\ Catholic University (PUCMM), \\ ${ }^{5}$ Department of Medicine, Santiago \\ Thechnological University (UTESA), \\ Santiago, Dominican Republic
}

This article was published in the following Dove Press journal:

Chronic Wound Care Management and Research

4 January 2017

Number of times this article has been viewed

Background: Soft tissue lesions represent a health problem of great magnitude around the world. Multiple drugs have been used in their treatment. Silver sulfadiazine (SSD) and silver nanocrystals (SNC) are among the most used. The purpose of this research was to compare the effectiveness of SSD and SNC regarding the wound granulation rate, treatment time, antibiotic effect, and treatment cost and to determine the frequency of these lesions in participants of this research.

Methods: Data were collected from 50 patients with soft tissue lesions in the Regional University Hospital José María Cabral y Báez (HRUJMCB), in Santiago, Dominican Republic. This study was approved by the bioethics committee of the Pontifical Catholic University Madre and Maestra (PUCMM) and the HRUJMCB. Patients were followed up from August 2015 to February 2016. SPSS Statistics program was used to calculate Chi square and assess statistical significance.

Results: Fifty patients were included in this study, of whom $56 \%$ had diabetic foot ulcers, $22 \%$ had vascular ulcers, and $22 \%$ had pressure ulcers. In total, $42 \%$ of the patients were treated with SSD and 58\% with SNC. Granulation rate was $71.4 \%$ for SSD and $89.6 \%$ for SNC, and positive antibiotic effect was $15.9 \%$ for SSD and $25.9 \%$ for SNC. A total of $14.4 \%$ of patients treated with SSD ended their participation in the research between 8 and 14 days, $37.9 \%$ in $15-21$ days, and $42.8 \%$ in $\geq 21$ days. For SNC, $3.4 \%$ of patients concluded their participation in $0-7$ days, $34.4 \%$ in $8-14$ days, $37.9 \%$ in $15-21$ days, and $24.1 \%$ in $\geq 21$ days. The distribution of economic costs in the SSD group was as follows: USD0-22, $42.9 \%$, and USD22-66, 57.2\%, while in the SNC group, the distribution was as follows: USD0-22, 48.2\%; USD22-66, 48.3\%; and USD66-110, 3.4\%.

Conclusion: There is no statistical significance in the results of this study; however, in percentage, SNC are superior regarding the rate of wound granulation, antibiotic effect, and healing time. Economic cost for both is similar.

Keywords: silver, sulfadiazine, nanocrystals, ulcers

\section{Introduction}

Soft tissue lesions constitute a group of clinical entities that affect a large segment of the hospital population in the Dominican Republic, as well as people who are not admitted to a specific health center but assist to the general surgery consults of various health centers in the nation. The most morbid among this group of complex wounds are vascular ulcers (both arterial and venous), pressure ulcers, and diabetic foot ulcers.

Unlike other wounds, the aforementioned types occur on tissues with underlying conditions and involve an inflammatory stage that extends over time. This makes treatment challenging and usually requires a multidisciplinary team to address the
Correspondence: Cristian Tineo Department of Surgery, Jose Maria Cabral y Baez Regional and University Hospital (HRUJMCB), Sabana Larga Avenue \#I, Santiago 51000,

Dominican Republic

Tel + I 8296770543

Email ctineosantana@hotmail.com 
management of these lesions as well as the combination of agents for the best progression of these injuries. For several decades, silver has been recognized for its antibiotic effectiveness and for its ability to remove devitalized tissue and to promote an ideal environment for wound healing; two particular formulas based on silver have taken the lead in the treatment of soft tissue injuries, silver sulfadiazine (SSD) and silver nanocrystals (SNC). ${ }^{1,2}$

Several recent investigations have shown the effectiveness of treatment with both nanocrystals and sulfadiazine. In fact, there have been some studies that have shown benefits on the use of these silver-based compounds over other preparations such as iodine not only with respect to wound granulation but also regarding their antibiotic effects against some specific microorganisms such as Staphylococcus aureus, Streptococcus pneumoniae, and Pseudomonas aeruginosa, with a very low rate of side effects. ${ }^{3-8}$ However, other studies have questioned these results, after comparing the effectiveness of silver-based compounds with other commonly used drugs. ${ }^{9,10}$ The purpose of this investigation was to determine the most frequent soft tissue lesions and to compare the effectiveness of nanocrystals and SSD with regard to the rate of granulation of wounds, the antibiotic effect, the duration of treatment, and the economic cost.

\section{Methods}

\section{Study design}

This study was approved by the bioethics committee of the Mother and Master Pontifical and Catholic University (PUCMM) and the Regional University Hospital José María Cabral y Báez (HRUJMCB) in Santiago, Dominican Republic. The research corresponded to a prospective, longitudinal study of primary and secondary source that compared the effectiveness of SNC and SSD with regard to the wound granulation rate, the antibiotic effect and the duration of treatment of the lesions in the study participants using either drug. The study also investigated the most frequent type of soft tissue lesion, the average economic cost per patient with one or the other drug, recruiting participants and analysis of the results occurred during the period of August 2015 to February 2016.

Fifty patients were included in the research who were afflicted with vascular ulcers, pressure ulcers, or diabetic foot ulcers. They were randomly assigned to one of the two groups. The inclusion criteria were patients who had vascular ulcers, pressure ulcers, or diabetic foot ulcers. All patients were $\geq 18$ years old and provided their written informed consent to participate in this study. Exclusion criteria were patients who had a previous allergic reaction to silver compounds and who were $<18$ years. Patients with immune disorders and those with lesions for $>6$ months were also excluded.

Patients in the SSD group received treatment every 24 hours. Patients in the SNC group had dressing changes every 7 days. Both types of dressings were generic compounds that are found commonly in drug stores, with similar side compounds such as fatty acids, triglycerides, and alcohols; the exactly same formulation of the dressings was used for every patient in each group. Lesion treatments were performed by cleaning the wounds with $10 \mathrm{cc}$ of saline solution $0.9 \%$ and dressing changes every 24 hours in the SSD group and weekly in the SNC group, as well as local debridement was performed in cases that required it. Some parameters were reviewed during each dressing change, such as size of the wound, presence of purulent secretions and presence of granulation tissue; these parameters were evaluated weekly in both groups and compared with the ones obtained the week before to assess the effect of the intervention. A culture of the lesion was taken before the beginning of the intervention and at the end of the intervention to evaluate the antibiotic effect. The final point of participation in the study was, when the wound was completely granulated or after the patient had been included in the research for 28 days or more, whether the wound was granulated or not. Granulation was determined clinically by observing the wound completely covered by granulation tissue using the criteria of a specialist in general surgery, who was always the same.

The program SPSS statistic version 23.0 (IBM Corporation, Armonk, NY, USA) was used to calculate the Chi square for each variable to assess the statistical significance.

\section{Variable definition}

In this research, five variables were measured. 1) The most frequent type of lesion; this corresponded to the number of participants who had each type of lesion. 2) The granulation rate of the lesion that represented the percentage of patients in whom the lesion presented complete granulation for each drug used. 3) The variable antibiotic effect represented the percentage of patients whom in the initial culture tested positive for a microorganism, but later in the final culture tested negative secondary to the use of either drug. 4) The duration of treatment corresponds to the period of time between the start of patients in the study and completion of the research either because the lesion was completely granulated or because they had overpassed the 28 days of treatment. 5) The economic cost is the average of money spent on the treatment of each patient during their participation in the study; this was calculated by the number of dressings by its individual price in Dominican pesos and in USD, days of hospitalization 
and other parameters were not used for this variable just the net price of the dressings in both groups.

\section{Results}

A total of $56 \%(n=28)$ of patients were found to have diabetic foot ulcers, $22 \%(n=11)$ had vascular ulcers, and $22 \%(n=11)$ had decubitus ulcers. Table 1 shows the frequency distribution in further detail.

\section{Granulation rate}

In total, $42 \%(n=21)$ of the study participants were treated with $\mathrm{SSD}$, in $71.4 \%(\mathrm{n}=15)$, the lesion granulated, while in $28.6 \%(n=6)$, the lesion did not present granulation tissue. In the SNC group, $89.6 \%(n=26)$ of the lesions presented granulation tissue, while $10.2 \%(n=3)$ of the same did not present granulation tissue; $P=0.66$, which implies that there is no statistical significance between these results. However, from the percentage point of view, there is superiority in this variable for the SNC compared to SSD. Table 2 shows the granulation rate for each type of lesion broken down according to each drug used in this research.

\section{Antibiotic effect}

For the SSD group, the antibiotic effect was $15.9 \%(n=3)$. It should be noted that in this group, the percentage calculation of the antibiotic effect was based on 19 patients, as from the 21 patients who originally had started treatment with SSD, two ended up being amputees, and final culture was not made so the drug action regarding the variable in question could not be assessed. For the SNC group, the antibiotic effect was $25.9 \%(n=7)$; in this case, the percentage calculation was performed based on 27 patients, because two of the 29 patients in this group had negative initial culture and they were not taken into account when assessing the antibiotic effect for this drug. The $P$-value for this variable was 0.35 . From the percentage point of view, there was remarkable superiority of SNC compare to SSD. Table 3 shows the difference in more detail.

Table I Frequency distribution of lesions for each stage

\begin{tabular}{|c|c|c|c|c|c|c|c|c|c|c|c|c|c|c|}
\hline \multirow{3}{*}{$\begin{array}{l}\text { Type of soft tissue lesions } \\
\text { PU }\end{array}$} & \multicolumn{14}{|c|}{ Distribution by type } \\
\hline & \multicolumn{3}{|c|}{ Grade I } & \multicolumn{2}{|c|}{ Grade II } & \multicolumn{3}{|c|}{ Grade III } & \multicolumn{4}{|c|}{ Grade IV } & \multicolumn{2}{|c|}{ Total } \\
\hline & 0 & \multicolumn{2}{|c|}{$0 \%$} & 3 & $6 \%$ & \multicolumn{2}{|c|}{8} & $16 \%$ & 0 & \multicolumn{3}{|c|}{\begin{tabular}{l|l} 
& $0 \%$ \\
\end{tabular}} & II & $12 \%$ \\
\hline \multirow[t]{2}{*}{$\mathrm{VU}$} & \multicolumn{4}{|c|}{ Venous } & \multicolumn{4}{|c|}{ Arterial } & \multicolumn{6}{|c|}{ Total } \\
\hline & 7 & \multicolumn{3}{|c|}{$14 \%$} & 4 & & \multicolumn{2}{|c|}{$8 \%$} & II & & & & \multicolumn{2}{|l|}{$22 \%$} \\
\hline \multirow[t]{2}{*}{ DFU } & \multicolumn{2}{|c|}{ Wo } & \multicolumn{2}{|c|}{ WI } & \multicolumn{2}{|c|}{ W2 } & \multicolumn{2}{|c|}{ W3 } & \multicolumn{2}{|c|}{ W4 } & \multicolumn{2}{|c|}{ W5 } & \multicolumn{2}{|l|}{ Total } \\
\hline & 0 & $0 \%$ & 0 & $0 \%$ & I & $2 \%$ & 27 & $54 \%$ & 0 & $0 \%$ & 0 & $0 \%$ & 28 & $56 \%$ \\
\hline Patient total & 50 & & & & & & & $100 \%$ & & & & & & \\
\hline
\end{tabular}

Abbreviations: PU, pressure ulcers; VU, vascular ulcers; DFU, diabetic foot ulcers.

Table 2 Granulation rate for each drug

\begin{tabular}{|c|c|c|c|c|c|c|c|c|}
\hline & & & & \multicolumn{3}{|c|}{ Type of lesion (n) } & \multirow[t]{2}{*}{ Total } & \multirow[t]{2}{*}{$P$} \\
\hline & & & & PU & VU & DFU & & \\
\hline \multirow[t]{6}{*}{ SSD } & Granulation rate & Granulation lesion & & 2 & 2 & II & 15 & 0.64 \\
\hline & & & $\%$ from total & 9.5 & 9.5 & 52.4 & 71.4 & \\
\hline & & Not granulated & & 0 & I & 5 & 6 & \\
\hline & & & $\%$ from total & 0.0 & 4.8 & 23.8 & 28.6 & \\
\hline & Total & & & 2 & 3 & 16 & 21 & \\
\hline & & & $\%$ from total & 9.5 & 14.3 & 76.2 & 100.0 & \\
\hline \multirow[t]{6}{*}{ SNC } & Granulation rate & Granulation lesion & & 8 & 7 & II & 26 & 0.95 \\
\hline & & & $\%$ from total & 27.6 & 24.1 & 37.9 & 89.6 & \\
\hline & & Not granulated & & I & I & 1 & 3 & \\
\hline & & & $\%$ from total & 3.4 & 3.4 & 3.4 & 10.2 & \\
\hline & Total & & & 9 & 8 & 12 & 29 & \\
\hline & & & $\%$ from total & 31.0 & 27.6 & 41.4 & 100.0 & \\
\hline \multirow[t]{6}{*}{ Total } & Granulation rate & Granulation lesion & & 10 & 9 & 22 & 41 & 0.66 \\
\hline & & & $\%$ from total & 20.0 & 18.0 & 44.0 & 82.0 & \\
\hline & & Not granulated & & 1 & 2 & 6 & 9 & \\
\hline & & & $\%$ from total & 1.0 & 2.0 & 12.0 & 15.0 & \\
\hline & Total & & & II & II & 28 & 50 & \\
\hline & & & $\%$ from total & 22.0 & 22.0 & 56.0 & 100.0 & \\
\hline
\end{tabular}

Abbreviations: PU, pressure ulcers; VU, vascular ulcers; DFU, diabetic foot ulcers; SSD, silver sulfadiazine; SNC, silver nanocrystals. 
Table 3 Antibiotic effect for each drug

\begin{tabular}{|c|c|c|c|c|c|c|c|c|}
\hline & & & & \multicolumn{3}{|c|}{ Type of lesion (n) } & \multirow[t]{2}{*}{ Total } & \multirow[t]{2}{*}{$P$} \\
\hline & & & & PU & VU & DFU & & \\
\hline \multirow[t]{6}{*}{ SSD } & Antibiotic effect & Positive & & 1 & 1 & 1 & 3 & 0.19 \\
\hline & & & $\%$ from total & 5.3 & 5.3 & 5.3 & 15.9 & \\
\hline & & Negative & & 1 & 2 & 13 & 16 & \\
\hline & & & $\%$ from total & 5.3 & 10.5 & 68.4 & 84.2 & \\
\hline & Total & & & 2 & 3 & 14 & 19 & \\
\hline & & & $\%$ from total & 10.5 & 15.8 & 73.7 & 100.0 & \\
\hline \multirow[t]{6}{*}{ SNC } & Antibiotic effect & Positive & & 3 & 0 & 4 & 7 & 0.25 \\
\hline & & & $\%$ from total & 11.1 & 0.0 & 14.8 & 25.9 & \\
\hline & & Negative & & 6 & 6 & 8 & 20 & \\
\hline & & & $\%$ from total & 22.2 & 22.2 & 29.6 & 74.0 & \\
\hline & Total & & & 9 & 6 & 12 & 27 & \\
\hline & & & $\%$ from total & 33.3 & 22.2 & 44.4 & 100.0 & \\
\hline \multirow[t]{6}{*}{ Total } & Antibiotic effect & Positive & & 4 & 1 & 5 & 10 & 0.35 \\
\hline & & & $\%$ from total & 8.7 & 2.2 & 10.9 & 21.8 & \\
\hline & & Negative & & 7 & 8 & 21 & 36 & \\
\hline & & & $\%$ from total & 15.2 & 17.4 & 45.7 & 78.3 & \\
\hline & Total & & & 11 & 9 & 26 & 46 & \\
\hline & & & $\%$ from total & 23.9 & 19.6 & 56.5 & 100.0 & \\
\hline
\end{tabular}

Abbreviations: PU, pressure ulcers; VU, vascular ulcers; DFU, diabetic foot ulcers; SSD, silver sulfadiazine; SNC, silver nanocrystals.

\section{Duration of treatment}

For this variable, the percentage of patients who completed treatment due to granulation of the lesion or the end of the research period for each drug was calculated observing that for SSD $14.4 \%(n=3)$ completed treatment in a time of 8-14 days, $42.9 \%(n=9)$ did between 15 and 21 days and $42.8 \%(n=9)$ in $>21$ days. In this group, two patients who were treated with SSD and became amputees at a later date were included since their amputations were decided only after the completion of 28 days of the study, this showed that the affected limb was not viable. As for the group of SNC, 3.4\% $(n=1)$ completed treatment between 0 and 7 days, $34.4 \%$ $(\mathrm{n}=10)$ between 8 and 14 days, $37.9 \%(n=11)$ between 15 and 21 days and the remaining $24.1 \%(n=7)$ completed treatment in $>21$ days. The $P$-value for this variable was 0.08 . On this topic, a higher percentage of patients, $75.7 \%(n=22)$, in the group of the SNC ended the study in $\leq 21$ days, compared with the SSD group in which only $57.3 \%(n=12)$ of patients treated with this drug ended before 21 days, showing the shortest duration of treatment in a greater percentage of patients, for the group of SNC. In Table 4, ranges of treatment time observed in each lesion and drug used in each group are presented.

\section{Economic cost}

With regard to economic cost, this variable was measured for each group of drugs; it was observed that for SSD, $42.9 \%$ $(n=9)$ completed treatment with an amount spent on the drugs between 0 and 1000 pesos (USD0-22), while 57.2\% $(n=12)$ spent between 1001 and 3000 pesos (USD22-66). In regards for SNC treatment, $48.3 \%$ of patients completed treatment with spending between 0 and 1000 pesos (USD0-22) ( $\mathrm{n}=14), 48.2 \%$ spent between 1001 and 3000 pesos (USD22-66) $(n=14)$, and 3.4\% spent between 3001 and 5000 pesos (USD66-110) $(\mathrm{n}=1), P=0.17$. From these results, it is evident that in $100 \%(\mathrm{n}=21)$ of patients treated with SSD, the cost of treatment was $<3000$ pesos (USD66), while in the SNC group, $96.5 \%(n=28)$ of patients completed treatment with an economic cost $<3000$ pesos (USD66), this does not reflect a significant difference between either drug in regards to the cost of treatment; however, it should be noted that these calculations only include the net cost of the drugs without counting the cost of the material used for performing the treatments nor the cost of debridements when needed. In Table 5, percentage values of each range of economic cost per lesion are presented for each group of drug.

\section{Discussion}

During the review of national and international literature, no research comparing directly the relationship between SSD and SNC treatment was found, in particular in soft tissue injuries that were evaluated in this study; however, comparisons were made between the results of this research with other studies with similar characteristics.

This study showed that in analyzing the effect of the drug in each type of lesion studied for each particular 
Table 4 Duration time of treatment for each drug

\begin{tabular}{|c|c|c|c|c|c|c|c|c|}
\hline & & & & \multicolumn{3}{|c|}{ Type of lesion (n) } & \multirow[t]{2}{*}{ Total } & \multirow[t]{2}{*}{$P$} \\
\hline & & & & PU & VU & DFU & & \\
\hline \multirow[t]{8}{*}{$\overline{S S D}$} & Duration of & 8-14 days & & $\mathrm{I}$ & 1 & I & 3 & 0.19 \\
\hline & treatment & & $\%$ from total & 4.8 & 4.8 & 4.8 & 14.4 & \\
\hline & & $|5-2|$ days & & I & 0 & 8 & 9 & \\
\hline & & & $\%$ from total & 4.8 & 0.0 & 38.1 & 42.9 & \\
\hline & & $=22$ days & & 0 & 2 & 7 & 9 & \\
\hline & & & $\%$ from total & 0.0 & 9.5 & 33.3 & 42.8 & \\
\hline & Total & & & 2 & 3 & 16 & 21 & \\
\hline & & & $\%$ from total & 9.5 & 14.3 & 76.2 & 100.0 & \\
\hline \multirow[t]{10}{*}{ SNC } & Duration of & $0-7$ days & & 0 & 1 & 0 & I & 0.57 \\
\hline & treatment & & $\%$ from total & 0.0 & 3.4 & 0.0 & 3.4 & \\
\hline & & 8-14 days & & 4 & 3 & 3 & 10 & \\
\hline & & & $\%$ from total & 13.8 & 10.3 & 10.3 & 34.4 & \\
\hline & & $|5-2|$ days & & 4 & 2 & 5 & 11 & \\
\hline & & & $\%$ from total & 13.8 & 6.9 & 17.2 & 37.9 & \\
\hline & & $=22$ days & & I & 2 & 4 & 7 & \\
\hline & & & $\%$ from total & 3.4 & 6.9 & 13.8 & 24.1 & \\
\hline & Total & & & 9 & 8 & 12 & 29 & \\
\hline & & & $\%$ from total & 31.0 & 27.6 & $4 I .4$ & 100.0 & \\
\hline \multirow[t]{10}{*}{ Total } & Duration of & $0-7$ days & & 0 & 1 & 0 & I & 0.08 \\
\hline & treatment & & $\%$ from total & 0.0 & 2.0 & 0.0 & 2.0 & \\
\hline & & 8-14 days & & 5 & 4 & 4 & 13 & \\
\hline & & & $\%$ from total & 10.0 & 8.0 & 8.0 & 26.0 & \\
\hline & & $|5-2|$ days & & 5 & 2 & 13 & 20 & \\
\hline & & & $\%$ from total & 10.0 & 4.0 & 26.0 & 40.0 & \\
\hline & & $=22$ days & & I & 4 & 11 & 16 & \\
\hline & & & $\%$ from total & 2.0 & 8.0 & 22.0 & 32.0 & \\
\hline & Total & & & 11 & II & 28 & 50 & \\
\hline & & & $\%$ from total & 22.0 & 22.0 & 56.0 & 100.0 & \\
\hline
\end{tabular}

Abbreviations: PU, pressure ulcers; VU, vascular ulcers; DFU, diabetic foot ulcer; SSD, silver sulfadiazine; SNC, silver nanocrystals.

Table 5 Economic cost for each drug

\begin{tabular}{|c|c|c|c|c|c|c|c|c|}
\hline & & & & \multicolumn{3}{|c|}{ Type of lesion (n) } & \multirow[t]{2}{*}{ Total } & \multirow[t]{2}{*}{$P$} \\
\hline & & & & PU & VU & DFU & & \\
\hline \multirow[t]{6}{*}{ SSD } & Economic cost & $0-1000$ pesos & & 1 & 2 & 6 & 9 & 0.63 \\
\hline & & (USD0-22) & $\%$ from total & 4.8 & 9.5 & 28.6 & 42.9 & \\
\hline & & $1001-3000$ pesos & & 1 & 1 & 10 & 12 & \\
\hline & & (USD22-66) & $\%$ from total & 4.8 & 4.8 & 47.6 & 57.2 & \\
\hline & Total & & & 2 & 3 & 16 & 21 & \\
\hline & & & $\%$ from total & 9.5 & 14.3 & 76.2 & 100.0 & \\
\hline \multirow[t]{8}{*}{ SNC } & Economic cost & $0-1000$ pesos & & 3 & 5 & 6 & 14 & 0.29 \\
\hline & & (USD0-22) & $\%$ from total & 10.3 & 17.2 & 20.7 & 48.2 & \\
\hline & & $1001-3000$ pesos & & 6 & 2 & 6 & 14 & \\
\hline & & (USD22-66) & $\%$ from total & 20.7 & 6.9 & 20.7 & 48.3 & \\
\hline & & $300 \mathrm{I}-5000$ pesos & & 0 & 1 & 0 & I & \\
\hline & & (USD66-II0) & $\%$ from total & 0.0 & 3.4 & 0.0 & 3.4 & \\
\hline & Total & & & 9 & 8 & 12 & 29 & \\
\hline & & & $\%$ from total & 31.0 & 27.6 & 41.4 & 100.0 & \\
\hline \multirow[t]{8}{*}{ Total } & Economic cost & $0-1000$ pesos & & 4 & 7 & 12 & 23 & 0.17 \\
\hline & & (USD0-22) & $\%$ from total & 8.0 & 14.0 & 24.0 & 46.0 & \\
\hline & & $1001-3000$ pesos & & 7 & 3 & 16 & 26 & \\
\hline & & (USD22-66) & $\%$ from total & 14.0 & 6.0 & 32.0 & 52.0 & \\
\hline & & $300 \mathrm{I}-5000$ pesos & & 0 & I & 0 & I & \\
\hline & & (USD66-II0) & $\%$ from total & 0.0 & 2.0 & 0.0 & 2.0 & \\
\hline & Total & & & 11 & 11 & 28 & 50 & \\
\hline & & & $\%$ from total & 22.0 & 22.0 & 56.0 & 100.0 & \\
\hline
\end{tabular}

Abbreviations: PU, pressure ulcers; VU, vascular ulcers; DFU, diabetic foot ulcer; SSD, silver sulfadiazine; SNC, silver nanocrystals. 
treatment, the percentage of the total granulation was $89.6 \%$ for SNC vs $71.4 \%$ for SSD, which shows that the performance of SNC was superior in the above variable. These findings are consistent with other studies; Klippstein et $\mathrm{al}^{11}$ in Spain showed the benefits of SNC in the reduction of inflammation, while Venkataraman and Nagarsenker ${ }^{12}$ in India demonstrated that SNC had better performance compared to SSD with respect to healing wounds, mainly by the favorable environment generated around them. Likewise, Tian et $\mathrm{al}^{1}$ in China argued that the SNC promoted wound healing and modulated the inflammatory process by controlling the release of cytokines. ${ }^{1}$ However, the above mentioned findings run counter to those of StormVersloot et al in the Netherlands, who concluded that there was insufficient evidence to show that compounds based on silver contributed to the healing of wounds. They did recognize the need to perform further investigation tasks related to this topic. ${ }^{9}$

With respect to the antibacterial effect, we found that SNC had a positive antibacterial effect in $25.9 \%$ of patients, while SSD had positive antibacterial effect in $15.9 \%$ of patients. This represents a percentage difference of $10.1 \%$ in favor of SNC. This coincides with the findings by Miller ${ }^{13}$ in Australia, who stated that SNC eliminates contamination of wounds in less time than other silver-based compounds, thus promoting faster healing of wounds. Our findings are also similar to those published by Lara et $\mathrm{al}^{14}$ in the United States, which recognized the antibacterial and antiviral potential of SNC, as well as those findings by Murphy and Evans ${ }^{15}$ also in the United States, who found that SNC have better antibiotic effect than SSD, especially against particular microorganisms. Furthermore, the data presented in this study are similar to Mohajeri-Tehran et al ${ }^{16}$ in Iran; these investigators found evidence of antibiotic effect from SNC in patients with diabetic foot ulcers; Sütterlin et al ${ }^{17}$ in Sweden concluded that the compounds based on silver, including SNC and SSD, are useful in neither eradicating microorganisms that colonize chronic wounds nor in preventing colonization of them. Other studies have also proved that the antibiotic effect of silver-based compounds is due to their good penetration into tissues, their safety and decreased healing time, as well as the low rate of microbial resistance related to them; however, regarding safety, some rare cases of hepatotoxicity and skin lesions have been reported. ${ }^{18-21,22}$ With regard to the treatment time, it was found that $75.7 \%$ of all patients treated with SNC presented wound granulation in $<3$ weeks, while in the case of the SSD, $57.3 \%$ granulated $<3$ weeks, demonstrating a substantial difference of $18.8 \%$ between the two drugs, demonstrating that the performance of SNC is higher than SSD in the time of treatment of soft tissue injuries. These findings are consistent with those reported by Woung and $\mathrm{Liu}^{8}$ in China, who found that SNC promoted wound healing more quickly than other silver-based compounds, primarily modulating the inflammatory process around the ulcer treatment. The results of this presentation also corroborated with those of Miller ${ }^{13}$ in Australia, where it was shown that the SNC had a rate of healing of wounds faster than other preparations based on silver, including SSD. Likewise, Li et $\mathrm{al}^{21}$ in China corroborated the findings of this study to establish that SNCs are more effective than other compounds based on silver, including SSD, as they accelerate the healing process and thus, promote faster healing wounds, mainly because they do not affect fibroblast function. ${ }^{23,24}$

With regard to economic cost, $100 \%$ of patients treated with SSD cost <3000 Dominican pesos (<USD66), compared to the SNC, in which $96.6 \%$ of patients ended the study under 3000 Dominican pesos (<USD66), which shows no significant difference in the economic cost in either medication; however, this discussion only included the net cost of the drug, without counting the necessary disposable material, because of the need to treat patients with SSD every 24 hours, the overall cost of treatment is increased somewhat more than the SNC since in the latter group the patients were treated once a week. These data are supported by the provisions of Silva et $\mathrm{al}^{25}$ in Brazil, who determined that treatment with SNC reduces the hospital stay of patients compared with management based on SSD, as well as the use of the SNC decreased the amount of dressings needed to heal wounds in comparison to SSD; this clearly resulted in a lower economic cost in patients who were treated with SNC.

MacGregor et al in England established similar findings to that observed in this investigation in that the compounds based on silver are affordable to the general population for the management of soft tissue injuries because they reduce economic spending in comparison with drugs of other class, particularly because they decrease the time necessary for wound healing and hospital stay, the frequency of dressing changes, and also because it reduced the need for analgesics during treatment. All of these factors added in final terms minimizes the economic cost required for the treatment of soft tissue injuries. ${ }^{26}$ Finally, in relation to economic cost, Miller ${ }^{13}$ in Australia demonstrated a 33\% reduction of total cost of the management of chronic wounds treated with SNC compared to the SSD, mainly because dressing changes was performed every 3-4 days, while in the case of the SSD, it was made daily. 


\section{Conclusion}

The results obtained in this research have no statistical significance; however, the data obtained from this study from a percentage point of view showed that treatment based on SNC was superior by improving the likelihood of granulation of soft tissue injuries, had a higher antibiotic effect and shorter duration of treatment, and was without an increase in net economic costs. In this investigation, we could not establish superiority for either drug regarding the economic cost. What is clear though, is that both options seem to be effective in managing vascular ulcers, diabetic foot ulcers, and pressure ulcers and are also accessible to the general population and health care institutions.

\section{Limitations}

There were some limiting factors that we had to deal with during this investigation that are very important to mention: due to low socioeconomical status in the population where the research was held, many patients in this study could not finish it because of their lack of adherence to the interventions schedule, so the sample had to be reduced to a number of just 50 patients. Another important limiting factor was that because of the same reason aforementioned about socioeconomical issues, the nutrition level of the patients included in this investigation was very low, and since nutrition level is very important for wound healing we do not know exactly what the impact of our interventions in a well-nourished population, such as in developed countries, would be.

\section{Disclosure}

The authors report no conflicts of interest in this work.

\section{References}

1. Tian J, Wong K, Ho C, et al. Topical delivery of silver nanoparticles promotes wound healing. Chem Med Chem. 2007;2(1):129-136.

2. Thomas G, Rael L, Bar-Or R, et al. Mechanisms of delayed wound healing by commonly used antiseptics. J Trauma. 2009;66(1):82-91.

3. Beam J. Topical silver for infected wounds. JAthl Train . 2009;44(5):531-533.

4. Miller C, Newall N, Kapp S, et al. A randomized-controlled trial comparing cadexomer iodine and nanocrystalline silver on the healing of leg ulcers. Wound Repair Regen. 2010;18(4):359-367.

5. Li W, Xie X, Shi Q, Duan S, Ouyang Y, Chen Y. Antibacterial effect of silver nanoparticles on Staphylococcus aureus. Biometals. 2011;24(1):135-141.

6. Lansdown A. A pharmacological and toxicological profile of silver as an antimicrobial agent in medical devices. Adv Pharmacol Sci. 2010;2010:910686.

7. Bermejo A, Clara L, D'Atri GM, et al. Consenso SADI-SAM-SADCACCVE. Guía para el manejo racional de las infecciones de piel y partes blandas - Parte III. [Guide for management of skin and soft tissue lesions Part III. Panama journal of infectology]. Revista Panameña de Infectologia. 2010;12(1):60-74. Spanish.
8. Woung KKY, Liu X. Silver nanoparticles - the real "silver bullet" in clinical medicine? Royal Soc Chem. 2010;12(1):125-131.

9. Storm-Versloot M, Vos C, Ubbink D, Vermeulen H. Topical silver for preventing wound infection. Cochrane Database Syst Rev. 2010;3:CD006478.

10. Bergin S, Wraight P. Silver based wound dressings and topical agents for treating diabetic foot ulcers. Cochrane Database Syst Rev. 2006;1:CD005082.

11. Klippstein R, Fernandez R, Castillo P, Zaderenko A, Pozo D [webpage on the Internet]. Silver Nanoparticles Interactions with the Immune System: Implications for Health and Disease. INTECH; 2010. Cap. 16. Available from: http://www.intechopen.com/books/silver-nanoparticles/silvernanoparticles-interactions-with-the-immune-system-implications-forhealth-and-disease. Accessed November 10, 2016.

12. Venkataraman $M$, Nagarsenker $M$. Silver sulfadiazine nanosystems for burn therapy. AAPS PharmSciTech. 2013;14(1):254-264.

13. Miller $C$. Science against microbial pathogens: communicating current research and technological advances. In: Méndez-Vilas A, editor. Examining the Efficacy of Silver and Cadexomer Iodine Dressings in Treating Wounds Compromised by Bacterial Burden: A Review of the Literature. FORMATEX; 2011. Available from: http://www.formatex.info/microbiology3/book/14-22.pdf. Accessed November 10, 2016.

14. Lara H, Garza-Treviño E, Ixtepan-Turrent L, Singh D. Silver nanoparticles are broad-spectrum bactericidal and virucidal compounds. J Nanobiotechnol. 2011;9(1):30-37.

15. Murphy PS, Evans GR. Advances in wound healing: a review of current wound healing products. Plast Surg Int. 2012;2012:190436.

16. Mohajeri-Tehran MR, Aalaa M, Aalaa AA, et al. Antimicrobial effects of silver nanoparticles coated leather on diabetic foot ulcer. Open Access Sci Rep. 2012;1:538.

17. Sütterlin S, Tano E, Bergsten A, Tallberg A, Melhus A. Effects of silverbased wound dressings on the bacterial flora in chronic leg ulcers and its susceptibility in vitro to silver. Acta Derm Venereol. 2012;92(1):34-39.

18. Gunasekaran T, Nigusse T, Dhanaraju M. Silver nanoparticles as real topical bullets for wound healing. J Am Coll Clin Wound Spec. 2012;3(4):82-96.

19. Prabhu S, Poulose E. Silver nanoparticles: mechanism of antimicrobial action, synthesis, medical applications, and toxicity effects. Int Nano Lett. 2012;2:32-42.

20. Rai M, Deshmukh S, Ingle A, Gade A. Silver nanoparticles: the powerful nanoweapon against multidrug-resistant bacteria. J Appl Microbiol. 2012;112(5):841-852.

21. Li C, Fu R, Yu C, et al. Silver nanoparticle/chitosan oligosaccharide/ poly(vinyl alcohol) nanofibers as wound dressings: a preclinical study. Int J Nanomed. 2013;8:4131-4145.

22. Bidgoli S, Mahdavi M, Rezayat S, Korani M, Amani A, Ziarati P. Toxicity assessment of nanosilver wound dressing in Wistar rat. Acta Med Iran. 2013;51(4):203-208.

23. Rigo C, Ferroni L, Tocco I, et al. Active silver nanoparticles for wound healing. Int J Mol Sci. 2013;14(3):4817-4840.

24. Oliveira R, Rouzé R, Quilty B, et al. Mechanical properties and in vitro characterization of polyvinyl alcohol-nano-silver hydrogel wound dressings. Interface Focus. 2014;4(1):20130049.

25. Silva MN, Taminato M, Beretta ALRZ. Comparative study of the efficacy of nanocrystalline silver dressing and silver sulfadiazine applied on burns in hospitalized patients. J Dental Med Sci. 2014;13(4): 63-67.

26. MacGregor L, Ayello EA, Carville A, et al. Uso adecuado de los apósitos de plata en las heridas. Consenso del grupo de trabajo de expertos. [Correct use of silver dressings in wounds. Experts work group consensus]. Wounds International; 2012. Available from: www. woundsinternational.com/pdf/content_10498.pdf. Accessed November 10, 2016. Spanish 


\section{Publish your work in this journal}

Chronic Wound Care Management and Research is an international, peer reviewed, open access, online journal publishing original research, reviews, editorials, and commentaries on the causes and management of chronic wounds and the major issues related to chronic wound management. Topics also include chronic wounds as comorbidities to other conditions, patient adherence to therapy, and the economic burden of chronic wounds. The manuscript management system is completely online and includes a very quick and fair peer review system, which is all easy to use. Visit http://www.dovepress.com/testimonials.php to read real quotes from published authors.

Submit your manuscript here: https://www.dovepress.com/chronic-wound-care-management-and-research-journal 